\title{
Cultura da inovação e racionalidade econômica no universo do pequeno empreendimento
}

\author{
Innovation culture and economic rationality in the universe of small firms

\section{La culture de l'innovation et la rationalité économique dans l'univers de la petite entreprise}

\author{
La cultura de la innovación y la racionalidad económica en el universo de las \\ pequeñas empresas \\ Antonia Colbari* \\ (alcolbari@terra.com.br)
}

Recebido em 23/07/2013; revisado e aprovado em 15/11/2013; aceito em 16/01/2014

\begin{abstract}
Resumo: A análise da implantação do projeto Agentes Locais de Inovação, descortinou dimensões relevantes relativas à elasticidade do conceito de inovação, aos desafios do aprendizado de práticas inovadoras e aos resultados de uma intervenção qualificada no âmbito dos pequenos empreendimentos, com vistas a facilitar a sua inserção sustentável nas dinâmicas locais de desenvolvimento.

Palavras-chave: Cultura da inovação. Agentes de inovação. Micro e pequena empresa.

Abstract: The analysis of the implementation of the project Agentes Locais de Inovação has indicated relevant dimensions about the elasticity of innovation concept, the challenges of learning of innovative practices and outcomes of a qualified intervention into small businesses, in order to facilitate their sustainable integration in the local development dynamics.

Key words: Culture of innovation. Innovation agents. Small businesses.

Résumé: L'analyse de la mise en œuvre du projet Agentes Locais de Inovação a montré les dimensions pertinentes liées à l'élasticité du concept d'innovation, les défis de l'apprentissage de pratiques innovantes et les résultats d'une intervention qualifiées dans les petites entreprises en vue de faciliter leur intégration durable dans la dynamique du développement local.

Mots-clés: Culture d'innovation. Agents de l'innovation. Micro et petites entreprises.

Resumen: El análisis de la ejecución del proyecto de Agentes Locais de Inovação mostró dimensiones relevantes relacionadas con la elasticidad del concepto de innovación, a los retos de aprendizaje de prácticas innovadoras y los resultados de una intervención en las pequeñas empresas a fin de facilitar a su inserción duradera en la dinámica del desarrollo local.

Palabras clave: Cultura de la innovación. Agentes de la innovación. Micro y pequeñas empresas.
\end{abstract}

\section{Introdução}

Tema em voga no discurso acadêmico e político, a crescente globalização da economia não tem promovido a uniformização do sistema econômico mundial, apesar do controle exercido pelas grandes corporações sobre as decisões de investimento, em nível nacional e mundial, e da maior integração e interdependência entre os setores produtivos. Aparentemente, uma contratendência se evidencia ao se constatar que grande parte da riqueza mundial continua sendo produzida no âmbito das economias locais - um universo de micro, pequenas e médias empresas operando em escala regional e local. A suposta dualidade entre um "circuito superior" da economia, associado à lógica das grandes empresas e do mercado globalizado, e um "circuito inferior", atrelado à lógica dos pequenos empreendimentos e do mercado (SANTOS, 2004), não exclui a complexidade das situações reais geradas pelas relações de subordinação/dependência, mas também pela relativa autonomia entre as dinâmicas desencadeadas a partir desses "circuitos".

O epicentro das ações e reflexões relativas ao mundo empresarial e aos fluxos econômicos permanece na grande corporação, sobretudo pelos seus impactos no desenvolvimento regional, nas relações de emprego e de trabalho, na constituição de redes sociopolíticas e na difusão de processos de aprendizagem tecnológica e organizacional. No entanto, registra-se a tendência de reconhecimento e valorização das micro e pequenas empresas (MPEs) pelos seus próprios predicados, e não a partir da arquitetura e das propriedades típicas das grandes corporações; elas não seriam apenas “bountiful” (GRANOVETTER, 1984),

* Universidade Federal do Espírito Santo, Vitória, ES, Brasil. 
pois se integram ativamente aos circuitos de produção e distribuição da riqueza, tornandose peças relevantes nas agendas de desenvolvimento. Um tipo de "externalidade positiva" decorreria da própria inserção das MPEs em um território, tornando convergentes, na agenda pública e privada, duas linhas de ação: a promoção do pequeno empreendimento e o desenvolvimento local.

Nesse ângulo, situa-se o movimento da sociedade brasileira em prol do pequeno empreendimento e de um modelo de desenvolvimento assentado nas "vocações" locais e nos arranjos de "concertação" movidos por interesses e atores emergentes a partir das dinâmicas desencadeadas nos territórios. A essa mobilização de diversos atores sociais credita-se o Estatuto da Microempresa e da Empresa de Pequeno Porte (Lei Geral), um marco institucional que assegura tratamento diferenciado aos pequenos negócios nos aspectos tributários, no acesso ao crédito e na participação nas aquisições de bens e serviços pelo poder público, além de medidas de estímulo à inovação, à educação empreendedora e ao associativismo.

No entanto, a força das "vocações" e dos atores locais não tem sido suficiente para a garantia da sustentabilidade econômica e social. Cada vez mais enfatizada na retórica do desenvolvimento local, a inovação - ou mais precisamente uma "cultura da inovação" enraizada no interior das empresas - tem sido destacada como o grande desafio para garantir a sobrevivência e a expansão dos micro e pequenos empreendimentos, que, no Brasil, representam cerca de $99 \%$ das unidades produtivas, 51,6\% dos empregos formais não agrícolas e 40\% da massa de salários (SEBRAE/DIEESE, 2012). Nesse contexto, um tipo de intervenção qualificada no âmbito interno das empresas se faz necessária. O eixo de análise deste artigo é justamente uma dessas iniciativas - o Projeto Agentes Locais de Inovação (ALIs), uma iniciativa do Sebrae Nacional, lançada em 2008.

O recorte empírico da pesquisa destacou o processo de implantação e sua execução no estado do Espírito Santo, no período 2009-2011. As fontes utilizadas foram os documentos e informações produzidos pela Unidade de Acesso à Inovação e Tecnologia do Sebrae-ES. A primeira parte do artigo é destinada a considerações teóricas sobre a retórica e as práticas da inovação na sociedade contemporânea; a segunda, sobre a presença da inovação na agenda do setor governamental e do setor empresarial; e a terceira se detém a uma abordagem descritiva sobre o Programa ALIs; e a quarta, aos resultados iniciais de sua operacionalização.

\section{A retórica da inovação}

A inovação está na ordem do dia, como palavra-fetiche revestida de unanimidade, repetida em vários discursos e em diversas situações, um imperativo econômico e uma obrigação social, portanto, imune a críticas. Apesar de ser um fenômeno estudado por várias disciplinas científicas, a forma de atuação da inovação permanece obscurecida pela heterogeneidade das empresas e dos setores econômicos (TIDD, 2001; BRITO et al., 2009). Se não há uma fórmula universal de inovação, observa-se, todavia, um amplo consenso acerca da relação positiva entre os indicadores de inovação, sobretudo os investimentos em Pesquisa e Desenvolvimento (P\&D), e o desempenho empresarial (CHENEY et al., 1991; TIDD, 2001; HALL, 1987).

Por sua vez, o destaque das habilidades em identificar as oportunidades criadas pelo mercado repôs incisivamente a relação entre inovação e empreendedorismo (BESANKO, et al., 2000; PORTER, 1989), estreitando a associação entre dinâmica capitalista e as ações e recursos de incentivo à inovação, incluindo os processos de aprendizagem e da difusão da tecnologia. Persiste, no entanto, a confusão conceitual entre a invenção (novas ideias e conceitos) e a inovação (novas combinações, rearranjos e explorações de recursos), que, eventualmente, pode acarretar em mudanças no próprio paradigma tecnológico ou produtivo existente.

A conceituação de inovação abrange um amplo espectro de mudanças, do qual não se excluem as inovações tecnológicas, mas são consideradas também as alterações incrementais em produtos, processos e em gestão (SCHUMPETER, 1982; OCDE, 2004; VALE et al., 2008); algumas delas resultam de mudanças invisíveis, muitas vezes em dimensões intangíveis como, por exemplo, em "serviços em geral, modelos de negócio, estratégias, marcas e processos" (ARBIX, 2010). A modalidade 
incremental da inovação em geral ocorre em contextos de carências de investimento empresarial em pesquisa e desenvolvimento e de ausência de uma cultura da inovação, da assimilação da inovação enquanto um valor cultural (GUIMARÃES, 2011).

É verdade que, historicamente, a inovação sempre foi vital para o desenvolvimento capitalista, porém, a partir da crise dos anos 1960 e 1970, o conhecimento se transformou na principal força produtiva, tornando o capital intelectual um ativo a ser expandido e em constante atualização, seja por meio do pensamento crítico e inovador, seja pela aprendizagem contínua, desenvolvida em espaços especializados e na prática do trabalho. Um forte aparato discursivo alinha empresas e governo na afirmação do caráter imperativo da inovação, por sua vez cada vez mais dependente da base de conhecimento, tornando ainda mais relevante a preocupação com a gestão de conhecimento no contexto organizacional e a gestão pública da ciência e da tecnologia como sustentáculos da produção de riqueza e do desenvolvimento social (MACIEL, 2002; DIAZ-ISENRATH, 2008; FONTENELLE, 2012).

Se o trabalho é criador de valor e a inovação é um valor, eleva-se a importância do sistema de formação de profissionais produtores de conhecimentos e da própria produção científica e tecnológica. Em um mundo de incertezas, ambiguidades, complexidades e riscos, as concepções gerenciais se configuram mais comprometidas com a busca das vantagens competitivas que podem ser extraídas do próprio conhecimento organizacional, gerando-se novos conhecimentos por meio da exploração das habilidades e dos talentos dos chamados colaboradores (THRIFT, 1997; LUNDVALL, 2003).

A importância dos avanços dos conhecimentos teóricos e as possibilidades de sua aplicação nas dinâmicas produtivas e sociais estreitam e redefinem as interações entre múltiplos atores. A aprendizagem da inovação depende do estreitamento dos processos de interação e cooperação entre o setor produtivo, no qual se materializam as inovações, e as instituições de ensino e de pesquisa e as agências de fomento (LUNDVALL, 2003). Diversas práticas serão justificadas pelas necessidades de se maximizarem as oportunidades de interação social, aprendizado e inovação (THRIFT, 1997). Assim sendo, o processo de inovação evidencia seu caráter social e sistêmico, reiterando a perspectiva neoschumpeteriana, pois, se a empresa continua a ser o principal agente inovador, isso se viabiliza por meio de sua inserção em um sistema mais amplo e complexo, que envolve aspectos econômicos, socioculturais e institucionais.

A ênfase na inovação associada à concepção de utilidade e de criação de valor para as organizações torna-se um dos traços mais marcantes na modelagem das interpretações sobre o mundo contemporâneo. O discurso da criatividade e da inovação tem, no momento presente, uma particularidade, pois, se antes as mudanças marcavam momentos específicos nas trajetórias das organizações, agora elas devem ser constantes, um fluxo contínuo.

A dependência do conhecimento e da inovação se torna mais incisiva em decorrência das novas formas de produção e de consumo, aumentando-se a importância das marcas, patentes e finanças (THRIFT, 2005). Os desafios de se manterem ou conquistarem posições sólidas no mercado global impulsionam a racionalidade instrumental, impondo a presença mais incisiva do conhecimento lógico, o refinamento do cálculo e da previsão que sustentam uma engenharia de produção e de consumo mais rápida, sem estoques e sob monitoramento e controle contínuos e efetivos, procedimentos estes inviáveis sem formas eficazes de gestão do conhecimento. Inovar sempre faz parte desse cálculo para se desfrutarem as "vantagens comparativas baseadas na antecipação" e assim manter as posições vantajosas no mercado (DUBAR, 2009, p. 120).

As adjetivações em voga - "soft", "líquido", "flexível" - sinalizam mudanças no capitalismo, sem, no entanto, desviá-lo da rota original, o avanço da racionalidade empresarial. A cultura ou espírito da inovação, algo que se pretende tão naturalizado, como se fizesse parte do "DNA das empresas", marca um avanço no processo histórico de racionalização no sentido weberiano, no qual todas as diversas esferas da vida estão subordinadas a uma lógica de pensamento e de ação baseada na racionalidade fins-meios: o poder de dominar o futuro pelo cálculo, pela previsão e assim obter os melhores resultados. 
Se globalizar é ao mesmo tempo descentrar as atividades produtivas, os núcleos de poder e as influências culturais e se submeter à velocidade das mudanças, descentralização e flexibilidade são palavras-síntese de um conjunto de processos que caracterizam a fase atual do desenvolvimento do capitalismo. Nas dimensões macro e microssocial, a flexibilidade é a propriedade que permite à organização contemporânea respostas rápidas, incluindo as possibilidades de se desfazer e se refazer em curto prazo, tendo em vista o pronto atendimento das demandas que se apresentam (THRIFT, 1997; FONTENELLE, 2008). A empresa inovadora e flexível se torna o modelo de organização que se impõe não apenas ao mundo empresarial, mas também às demais instituições que não estão inseridas na lógica do mercado.

Por sua vez, se a configuração técnicaeconômica não se sustenta dissociada de um novo discurso, o circuito cultural do capitalismo tem facilitado "um maior compartilhamento linguístico entre academia e mundo dos negócios com o uso da palavra cultura" (FONTENELLE, 2012, p. 103), inclusive na expressão "cultura da inovação". A incorporação da cultura da inovação ao discurso empresarial e ao das agências promotoras de políticas públicas torna-se compreensível em um repertório mais ampliado de signos e significados em que outras expressões, como empreendedorismo e desenvolvimento, também se revestiram de elevada positividade, configurando uma espécie de discurso moral (e vital) da época. Alçados à condição de sobrevivência das organizações e da sociedade, as artes de empreender, inovar e desenvolver se impõem, desarmando as tentativas de crítica e de questionamento. Para Thrift (2005), trata-se do "circuito cultural do capitalismo", para Boltanski e Chiapello (2009), umas das marcas do novo espírito do capitalismo.

\section{A inovação na agenda brasileira}

São muitos os estudos que abordam as políticas públicas de fomento da inovação ancoradas na presença do Estado como instância reguladora capaz de garantir as condições de inovação, atualmente menos dependente de um "gênio inventor" ou do "ethos pessoal de um empreendedor" e muito mais da pesquisa científica. Se a visão mais heroica da invenção e da inovação está superada, tornam-se mais estreitas e relevantes as articulações entre o Estado, as empresas e os centros de pesquisa, tanto em resposta à lógica econômica atrelada às necessidades de rentabilidade privada imperante nos mercados quanto à lógica política, uma questão de poder, um assunto de Estado (DUBAR, 2009). Cabe ao poder público, a responsabilidade de criar um ambiente político e institucional favorável ao investimento empresarial em pesquisa científica e desenvolvimento tecnológico, seja individualmente ou em parcerias com os centros produtores de conhecimento.

Segundo Salerno e Kubota (2008, p. 17), no Brasil, as políticas de inovação "constituiriam o amálgama das políticas de ciência, de tecnologia e industrial". Várias propostas apresentadas objetivam o aperfeiçoamento do Sistema Nacional de Inovação - o conjunto de agentes e de instituições (empresas, universidades e agências governamentais) articulados em práticas sociais de fomento da inovação (CAMPOS, 2003; CASSIOLATO, et al., 2005) voltadas para capacitar e qualificar as empresas, tendo em vista a elevação da competitividade da economia brasileira (ARBIX, 2010). No entanto são muitos os entraves a essa realização, por exemplo: aos empresários faltaria a percepção mais apurada acerca do caráter estratégico do conhecimento para o incremento dos negócios, e aos pesquisadores acadêmicos, a preparação adequada para atuarem em atividades de Pesquisa e Desenvolvimento (P\&D) (GUIMARÃES, 2011).

Não cabe no escopo deste artigo uma análise mais sólida desses discursos, tampouco o tratamento mais apurado das iniciativas do governo, das empresas e das instituições de pesquisa no campo da inovação. Mas cabe mencionar algumas iniciativas e normatizações voltadas à criação de um ambiente favorável à inovação, incluindo mecanismos de melhor aproveitamento da base de ciência e tecnologia disponível, por meio das interações entre o setor produtivo e a produção científica. Merece destaque, em 2004, a criação dos Fundos Setoriais e a Política Industrial, Tecnológica e de Comércio Exterior (PITCE) e a Lei de Inovação; em 2005, a Lei n. 11.196/95 (Lei do Bem); e, em 2007, a Lei n. 11.540/07 que regulamentou o Fundo Nacional de Desenvolvimento Científico e 
Tecnológico (NARETTO et al., 2004; ARBIX, 2010; SOBRAL, 2011; IPEA, 2012).

No campo empresarial, os documentos Políticas públicas de inovação no Brasil: a agenda da indústria e a Agenda Legislativa da Indústria são emblemáticos para o entendimento da posição da CNI sobre a inovação nas empresas. Além do reforço da articulação entre as agências de fomento, institutos de pesquisa e órgãos públicos do sistema de ciência, tecnologia e inovação, os documentos propõem a afinação da sintonia dessas instituições com o intenso ritmo das inovações e da competitividade no plano internacional (CNI, 2005; 2012).

Na proposta de municipalização da Lei Geral da Pequena Empresa, elaborada pelo Sebrae, preconizam-se medidas de estímulo à inovação, entre elas a articulação dos municípios com as agências de fomento, universidades e outras instituições de pesquisa básica ou aplicada. Seriam parcerias destinadas a desenvolver projetos de educação tecnológica que facilitem a transferência de conhecimento gerado nas instituições de pesquisa e a formação de trabalhadores capacitados para emprego de novas técnicas de produção. Não menos relevante seria a criação, em âmbito municipal, de núcleos de inovação tecnológica e de incubadoras de empresas e a instituição de uma Comissão Permanente de Tecnologia e Inovação (CNM/SEBRAE, 2011).

Um dos arranjos institucionais destinados ao fomento da inovação no segmento da empresa de pequeno porte envolve o Sebrae e o $\mathrm{CNPq}$, agora parceiro do programa ALI, para o qual concede as bolsas aos agentes e ao coordenador, o programa. O CNPq já é o executor de um programa de intervenção direta nas empresas para fomento da inovação - o Programa de Formação de Recursos Humanos para o Desenvolvimento Tecnológico (RHAE), criado em 1987, que se vale do espectro de bolsas de Fomento Tecnológico para capacitar recursos humanos aptos ao desenvolvimento e aplicação de tecnologias e para alocar pesquisadores nas atividades de P\&D desenvolvidas nas empresas. Em 2007, o financiamento de projetos com o objetivo de inserir pesquisadores (mestres e doutores) foi estendido às micro, pequenas e médias empresas ${ }^{1}$.

\footnotetext{
1 Documento oficial em: <www.cnpq.gov.br>. Acesso em: 10 maio 2012.
}

Todavia o espaço na agenda governamental destinado ao fomento da inovação no universo do pequeno empreendimento não é objeto de consenso. A atuação da FINEP na concessão de subvenções diretas às empresas interessadas no desenvolvimento de produtos ou processos inovadores foi objeto de avaliação realizada pelo IPEA (2012). Nessa avaliação, questionou-se a estratégia de prioridade aos projetos oriundos de MPEs, cuja capacidade de gerar impactos na competitividade da economia é reduzida quando comparada à dos projetos de maior porte e de maior densidade tecnológica, frequentemente apresentados pelas médias e grandes empresas.

A despeito dessa avaliação, a inovação no universo das MPEs tem sido justificada pelos imperativos da sobrevivência no competitivo mundo corporativo. Nesse segmento específico, a incorporação da inovação na dinâmica organizacional demanda programas especiais, entre eles o projeto Agentes Locais de Inovação, implantado pelo Sebrae em vários estados brasileiros.

\section{Os agentes locais de inovação (ALIs)}

Na operacionalização de políticas públicas, tem sido constante a presença de diversas modalidades de agentes: de desenvolvimento, de inovação, comunitário de saúde, entre outros. Trata-se de agentes públicos de intervenção social que, ao socializar informações, conhecimentos e experiências, combinam as funções de educador social, de "técnico social" e de assessor especializado. Gradativamente, a operação de políticas públicas tende a explicitar os contornos de um conjunto de tarefas e funções específicas que parecem adquirir o lastro de uma profissão para a qual um perfil está sendo desenhado: ser portador de conhecimentos técnicos específicos, mas também certos traços de personalidade que facilitem a comunicação, a receptividade às diferenças e a capacidade de adaptação às diversas situações (COLBARI, 2012).

No caso em destaque neste artigo, os agentes são os executores de um programa de inovação de caráter gratuito e continuado e operacionalizado por meio de atendimentos diretos no local do estabelecimento, tendo como objetivo incrementar a inovação e a 
difusão de tecnologias no segmento da pequena empresa, além de garantir a aplicação dos recursos públicos previstos na Lei Geral para esta finalidade (SEBRAE, 2011). Atribuise a eles a tarefa de sensibilizar e mobilizar o empresário para as atitudes que favorecem a ruptura com as posturas tradicionais e também a incorporação da inovação no cotidiano da empresa. Acionando iniciativas individuais ou por meio dos arranjos produtivos integrados, devem facilitar o acesso do empresário à base disponível de informação e de conhecimentos científicos, tornando as empresas mais equipadas para o enfrentamento dos desafios do mercado².

Nos termos do edital de seleção ${ }^{3}$, os agentes de inovação devem ser "pessoas de perfil pró-ativo", capacitados para a operação direta nas funções empreendedoras internas ao pequeno negócio, inclusive nas relações entre as empresas e seus clientes e fornecedores. Sua postura deve ser "colaborativa" para atuar em conjunto com o proprietário e sob a supervisão de um consultor especializado com o intuito de rastrear as oportunidades produtivas e tecnológicas ainda não aproveitadas; incentivar a diversificação e a qualidade dos produtos; e estimular as mudanças no perfil gerencial e organizacional da empresa atendida.

Para o Sebrae, o Projeto ALI se inspira em experiências já realizadas em outros países, com o propósito de formar "extensionistas urbanos", em particular em um programa implantado na Índia no qual agentes locais de inovação atendiam empresas urbanas de uma determinada área ${ }^{4}$. Estende-se para o contexto urbano a prática do extensionismo rural (agentes externos que levam informações técnicas diversas ao campo com vistas a elevar a produtividade e a qualidade da produção do setor).

No estado do Espírito Santo, o projeto teve início em 2009, mediante parceria entre o Sebrae-ES e a Fundação de Amparo à Pesqui-

\footnotetext{
${ }^{2}$ Fabio Procópio. Profissão: Agente local de inovação. Agência Sebrae de Notícias, 21 jul. 2011. Acesso em: 3 maio 2012.

${ }^{3}$ Processo Seletivo SEBRAE/ES n. 05/2011, publicado em 06 nov. 2011. Disponível em: <www.sebraees.com.br>.

${ }^{4}$ Informações extraídas de Agência Sebrae de Notícias, de 14 abr. 2008. Disponível em: <www.sebrae.com.br>. Acesso em: $1^{\circ}$ ago. 2009.
}

sa do Espírito Santo (Fapes). Nesse momento, foram selecionados catorze agentes, que atenderam aproximadamente 700 empresas, contando com a orientação de dois consultores seniores. Em 2012, houve alterações no formato do projeto, entre elas, o convênio com o CNPq, responsável pela concessão de bolsas aos ALIs, e a abrangência limitada às pequenas empresas, em contraste com o período 2009-2011, quando vinte e dois por cento das empresas atendidas eram micro.

Ao Sebrae, além da seleção, da capacitação dos agentes e do gerenciamento da operacionalização do programa, cabe a mobilização das associações empresariais para a divulgação do programa e sensibilização das empresas enquadradas no escopo de sua cobertura. Porém fica a cargo dos agentes a prospecção das empresas a serem visitadas nas áreas, cidades e regiões delimitadas.

Quanto à capacitação dos ALIs, o processo tem a duração de aproximadamente dois meses (carga horária mínima de 144 horas), no decorrer do qual devem ser desenvolvidas as competências cognitivas (domínio de informações e conceitos relativos à pequena empresa, inovação e gestão); as competências de aplicação (habilidades de comunicação, de análise, avaliação e diagnóstico, de negociação e de arbitragem em situações de conflitos, de proposição de soluções; e domínio de instrumentos, como diagnóstico empresarial, diagnóstico "radar da inovação" e a ferramenta para elaboração do plano de ação); e as competências atitudinais (predisposição à convivência, à interação e ao trabalho em equipe; flexibilidade e visão sistêmica, entre outras) (SEBRAE/UCSEBRAE, 2012).

Após o período de capacitação, os treinandos iniciam a atuação direta nas empresas por meio de visitas regulares, no decorrer das quais observam, avaliam potencialidades e dificuldades e interagem com os agentes produtivos. A análise das impressões e informações colhidas nas empresas gera a consolidação do diagnóstico que servirá de base para a formulação de um plano de trabalho específico para as necessidades de cada unidade. Se for o caso, caberá ao ALI “identificar uma instituição ou profissional que detenha a expertise (conhecimento e capacidade) para prover a solução da empresa", assim como facilitar a aproximação entre o empresário 
e a instituição/empresa capaz de atender as demandas apresentadas ${ }^{5}$.

A implantação das ações de inovação, o monitoramento de seus resultados e a satisfação do empresário serão acompanhados e apoiados pelos ALIs, reforçando-se o perfil de sua atuação: a combinação de diagnóstico, orientação e intervenção dialogada. Sustentam essas ações as crenças de que atitudes e motivações inovadoras não dependem apenas de impulsos internos ou do contexto político institucional e de fatores socioculturais; elas podem ser aprendidas e desenvolvidas por meio de orientação especializada. O trabalho dos agentes é um trabalho de socialização, de orientação para a mudança de comportamentos e de práticas.

Transcorrido um ano da primeira intervenção, os agentes retornam para um segundo diagnóstico, com o objetivo de verificar se a cultura da inovação se implantou; se houve mudança na mentalidade dos proprietários no sentido de incorporar a inovação nas rotinas do negócio; e se ocorreu a passagem da postura reativa, em que se é induzido a inovar pelas pressões (necessidade de sobrevivência), à postura proativa, a inovação por empreendedorismo, desencadeada pela motivação e pela busca de diferenciação da concorrência e de liderança no mercado.

$\mathrm{Se}$, em geral, faltam às pequenas empresas a capacitação técnica e as atitudes inovadoras, os ALIs estão sendo treinados para visualizarem as dificuldades e potencialidades das empresas, atuarem na mudança de mentalidade dos empresários, contribuindo, por conseguinte, para a difusão da cultura inovadora nas rotinas dessas organizações.

\section{Os resultados de uma experiência}

De antemão, nota-se que mensurar a inovação no nível da empresa não é uma tarefa fácil ${ }^{6}$, em particular pela ausência de um modelo capaz de "relacionar as entradas (input) do processo de inovação, os processos internos da empresa por meio dos quais a

\footnotetext{
${ }^{5}$ Processo Seletivo SEBRAE/ES n. 05/2011, de 6 nov. 2011. Disponível em: <www.sebraees.com.br>.

${ }^{6}$ Uma análise a respeito de várias abordagens sobre as métricas utilizadas para operacionalizar a inovação encontra-se em Brito et al. (2009).
}

empresa processa as entradas (throughput) e os resultados do processo de inovação (output), relacionando todas essas dimensões do processo inovador com o desempenho das empresas" (BRITO et al., 2009, p. 8).

A título de contextualizar os resultados específicos captados no universo de empresas atendidas pelos agentes de inovação no Espírito Santo, destacam-se alguns dados extraídos de uma pesquisa de abrangência nacional, realizada em 2008, com uma amostra de 4.200 MPEs integrantes dos setores: indústria, comércio e serviços. No período de doze meses que antecedeu à realização da pesquisa, 25\% das MPEs introduziram um novo processo ou método na sua rotina; $24 \%$ introduziram um novo produto ou serviço; e $17 \%$ conquistaram um novo mercado. Quanto ao grau de inovação, as MPEs foram classificadas da seguinte forma: $54 \%$ foram consideradas não inovadoras (sem realizar qualquer inovação); $43 \%$ eram inovadoras (alguma inovação de produto ou processo ou mercado); e $4 \%$ eram muito inovadoras (inovação de produto e de processo e de mercado) ${ }^{7}$ (SEBRAE-SP, 2009).

Esses resultados traduzem em números o diagnóstico a respeito do tipo e das razões das dificuldades enfrentadas pelo segmento. Apesar do destaque na geração de emprego e renda e na descentralização do desenvolvimento, as MPEs caracterizam-se pela grande fragilidade, como indicam as taxas de mortalidade no setor.

As ações e programas destinados ao setor devem levar em conta suas especificidades que incidem diretamente nas perspectivas de inovação, tais como: a carência de um nível adequado de organização nos aspectos contábeis, gerenciais e estruturais; e a não disponibilidade de profissionais qualificados para responder às exigências das instituições de fomento de inovação, sobretudo aquelas decorrentes da gestão, acompanhamento e finalização dos projetos. Além disso, nesse segmento, prevalecem as necessidades mais imediatas, a prioridade dos resultados de

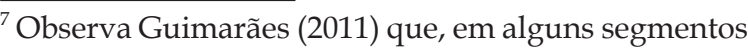
de pequenas empresas, são identificadas características favoráveis à inovação, tais como as trajetórias mais diversificadas e a exposição a níveis mais intensos de competição, fatores que podem estimular a propensão ao risco e o desembaraço para o enfrentamento da incerteza e da diversidade.
} 
curto prazo e o baixo conhecimento acerca da importância da inovação e das questões tecnológicas relativas às áreas de atuação da empresa (MDIC, 2007).

Trata-se de um quadro no qual atuam fatores complexos, muitos de categoria estrutural, desafiando a imaginação das instituições formuladoras e executoras de políticas públicas destinadas ao pequeno negócio. O caráter recente da implantação do Projeto ALI não permite ainda visualizar resultados efetivos e consistentes a respeito de sua eficácia. Se o objetivo é desenvolver uma cultura de inovação, transitar das inovações ocasionais para as sistemáticas, é preciso um tempo mais longo para se aferirem os resultados, além de se definirem os indicadores que permitam avaliar se essa "cultura" foi ou está sendo "produzida", se a inovação está sendo "cultivada".

Um processo avaliativo em duas etapas tem sido recomendado: a primeira, na qual devem ser captados os resultados de curto prazo (as inovações ocasionais), como a implantação de soluções de inovações nos processos e nos produtos e serviços; e outra etapa em que se avalia, em um prazo mais dilatado, a incorporação da inovação de forma sistemática. Em ambos os momentos, o desafio é perceber as pequenas variações, mas que podem ter impactos significativos no desempenho das empresas e em suas relações sinérgicas com o ambiente econômico em geral.

No período de novembro de 2009 a outubro de 2011, a execução do Projeto ALI no estado do Espírito Santo envolveu visitas, diagnósticos e intervenções em 695 empresas, sendo 542 (78\%) pequenas e 153 (22\%) microempresas. Nesse total, segundo o Sebrae-ES (2012), as empresas alocavam-se nos seguintes setores: Alimentício (16\%); Agroturismo (8\%); Construção Civil (13\%); Mármore e Granito (1\%); Metal Mecânico (4\%); Móveis (8\%); Turismo (23\%) e Vestuário (27\%).

O acompanhamento dos resultados dessas ações orientou-se por treze critérios, adaptados pelo Sebrae com base nas recomendações do Manual de Oslo, cuja concepção de inovação é ampla, cobrindo vários aspectos da dinâmica empresarial. O gráfico, a seguir, apresenta, seguindo esses critérios, a evolução do total das empresas atendidas pelos ALIs.

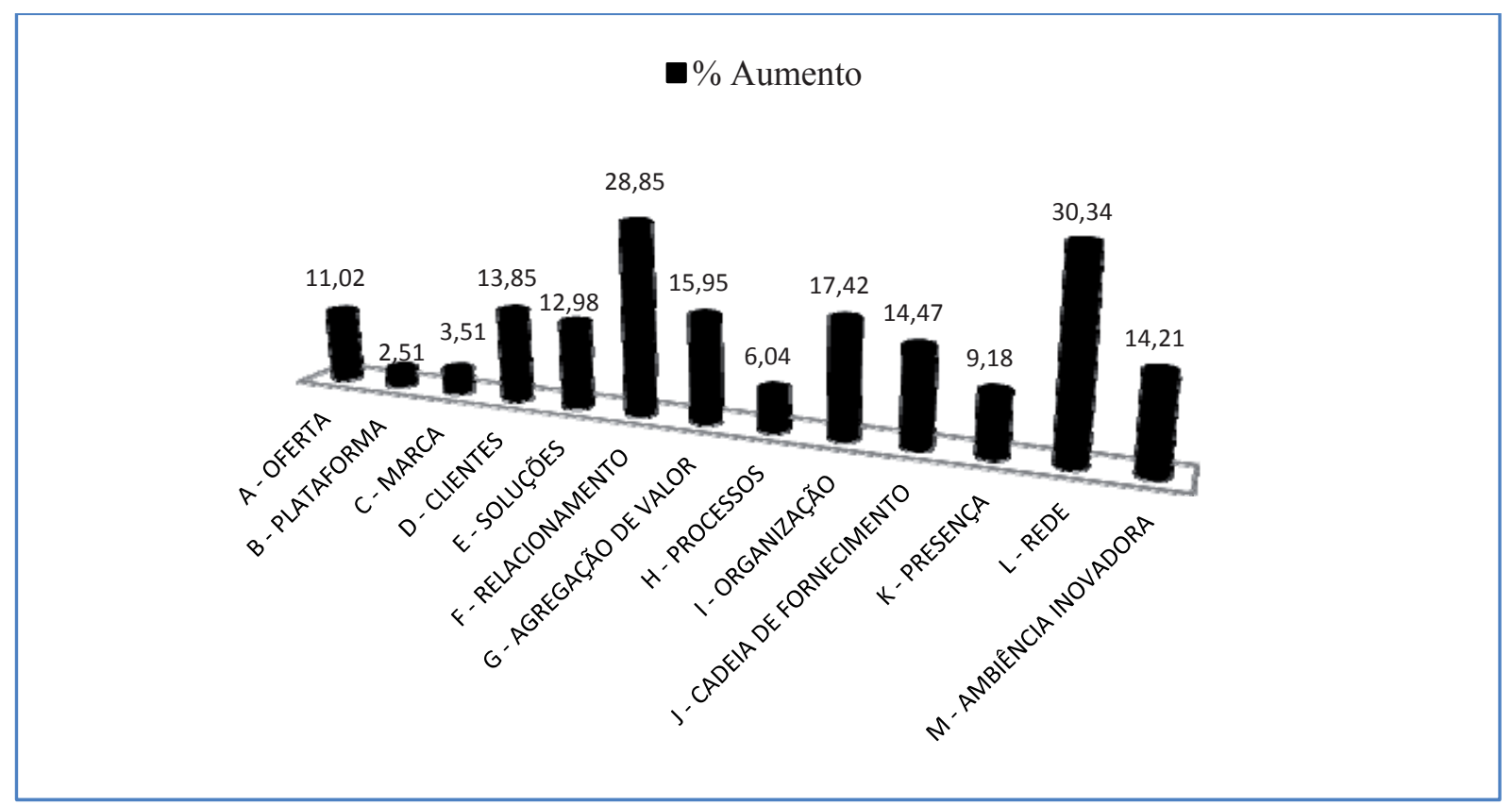

Gráfico 1 - Percentual de Inovação nas Empresas Diagnosticadas no Espírito Santo Fonte: Sebrae-ES (2012, p. 5). 
Observa-se o registro de melhores desempenhos em inovação nos critérios Rede e Relacionamento: o primeiro se reporta à capacidade de se comunicar e de reconhecer a importância de ouvir os clientes, e o segundo, às ferramentas utilizadas nas relações com os clientes. A seguir, aparecem os percentuais relativos à Organização (estrutura da empresa), Ambiência Inovadora (recursos humanos e articulações com órgãos de consultoria e pesquisa) e Clientes (recursos para identificar as necessidades dos mercados e clientes; para lançar novos produtos/serviços) (BACHMANN; DESTEFANI, 2008). Apesar de tímidos, os resultados são coerentes e promissores tendo em vista o cenário estadual e nacional, evidenciado pela Pesquisa de Inovação Tecnológica (Pintec), realizada pelo IBGE em 2008, em que a taxa de inovação permanece abaixo daquelas encontradas nos países desenvolvidos, além de concentrada em aquisição de novos equipamentos em detrimento do investimento das empresas em P\&D (ARBIX, 2010; IPEA, 2012).

A timidez da inovação nas empresas brasileiras é fato, porém há que se ressaltar a necessidade de refinamento da grade de indicadores tendo em vista a captura de processos sutis e nem sempre desencadeados por investimentos formais em inovação. Constatam-se, nas empresas de porte médio ou pequeno, práticas informais de $\mathrm{P} \& \mathrm{D}$, em geral voltadas para a imitação, a cópia e a absorção de tecnologias, e que são capazes de alterar positivamente o desempenho da empresa e da economia. Apesar de frágil ou inexistente o vínculo entre conhecimento e inovação e do baixo ou inexistente investimento em $P \& D$, algumas pequenas empresas têm sido capazes de promover inovações de produto, processo e de serviços por meio de parcerias com universidades e centros de pesquisa, ocorrências mais comuns em empresas de base tecnológica (GUIMARÃES, 2011), ou pela adaptação de ideias, estilos e tecnologias oriundos de outras empresas (ARBIX, 2010).

\section{Comentários Finais}

Alguns aspectos referentes à concepção e à prática da inovação mereceram uma exploração analítica mais consistente. Um deles reporta à constatação de que se aprende a inovar, pois atitudes e motivações inovadoras podem ser desenvolvidas por meio de orientação especializada. Reafirma-se, assim, uma prática corrente no mundo empresarial de se adquirir conhecimentos por meio de contratações e consultorias, investimento em marketing, na relação com usuários, na comercialização, entre outras. O desafio para a atuação do ALI é, portanto, a adequação dessa prática às características e às possibilidades do pequeno empreendimento.

Outro aspecto digno de nota é o conceito elástico de inovação, um processo de várias facetas, abrangendo imitação, experimentação, design, desenvolvimento e pesquisa, e que pode ser promovido por meio de diversas atividades - organizacionais, financeiras, comerciais e mercadológicas. Um dos alvos do Projeto ALI é justamente a desmistificação do processo de inovação, esta em muitas situações desvinculada da incorporação de tecnologias de ponta e restrita a aspectos da própria realidade do empresário.

A cultura da inovação, no sentido elástico em que é incorporada pelo programa ALIs, pode ser vista como uma tentativa de modelar os pequenos empreendimentos segundo um padrão de racionalidade científica e econômica que estimula a substituição de procedimentos tradicionais por outros de maior eficácia no plano técnico e financeiro. É uma estratégia de modernização do pequeno empreendimento na qual se procura, por meio da consultoria e do acompanhamento direto, desenvolver os atributos do empreendedor shumpeteriano, uma demonstração da crença de que se aprende a inovar. O ALI é o coroamento dessa ideia: é preciso ensinar/ aprender a inovar e introduzir nas empresas o cultivo da inovação.

Em um contexto mais amplo das políticas de fomento da inovação, o projeto ALI merece destaque por atuar no reduto dos pequenos negócios, estimulando MPEs ao acesso ao conhecimento e à incorporação do "espírito" da inovação. O projeto em si é uma inovação organizacional no âmbito da própria instituição Sebrae, que, além de manter o atendimento em seus espaços, agrega um programa que vai até o pequeno empreendedor.

O caráter recente do programa ainda não permite uma visão mais precisa dos resultados do trabalho dos agentes, em particular 
da contribuição efetiva para promover mudanças nas pequenas empresas e o desenvolvimento de uma cultura de inovação. Por sua vez, a avaliação dessa ação específica não pode ser descontextualizada de um movimento histórico no qual a inovação se tornou uma força produtiva decisiva para a racionalidade capitalista moderna.

Tomando a racionalidade como um fenômeno amplo, observa-se um duplo movimento: por um lado, as dinâmicas econômicas estão mais dependentes do conhecimento e da inovação, justificando-se a presença mais incisiva do Estado nesse terreno; e, por outro, uma política de inovação é um fenômeno complexo e sistêmico que, além de uma "boa ciência" possível de ser aplicada na base produtiva, depende também da existência de empresas interessadas em inovar, uma espécie de mercado para a inovação.

Estimular a inclusão da pequena empresa no circuito da inovação pode ser uma forma de se ampliar esse mercado.

\section{Referências}

ARBIX, G. Estratégias de inovação para o desenvolvimento. Tempo Social, São Paulo, v. 22, n. 2, p. 167-185, nov. 2010.

BACHMANN, D. L.; DESTEFANI, J.H. Metodologia para estimar o grau de inovação nas MPE: cultura do empreendedorismo e inovação. Bachmann $\mathcal{E}$ Associados, Curitiba, 2008. Disponível: em: <http://www.bachmann.com.br/ website/documents/ArtigoGraudeInovacaonasMPE. pdf>. Acesso em: 02 out. 2013.

BESANKO, D.; DRANOVE, D.; SHANLEY, M. Economics of Strategy. NewYork: Wiley, 2000.

BOLTANSKI, L.; CHIAPELLO, E. O novo espírito do capitalismo. São Paulo: Martins Fontes, 2009.

BRITO, E. P. Z.; BRITO, L. A. L.; MORGANTI, F. Inovação e o desempenho empresarial: lucro ou crescimento? RAE-eletrônica, São Paulo, v. 8, n. 1, jan./jun. 2009. Disponível em: <http://rae.fgv.br/rae-eletronica/ vol8-num1-2009/inovacao-desempenho-empresariallucro-ou-crescimento>. Acesso em: 13 jun. 2013.

CAMPOS, F. L. S. Sistema nacional de inovação, produtos e dinâmica tecnológica: uma abordagem neoschumpeteriana. In: CONGRESSO BRASILEIRO DE GESTÃO DE DESENVOLVIMENTO DE PRODUTO, 4., 2003, Gramado, RS. Anais... Gramado, 2003.

CASSIOLATO, J. E.; LASTRES, M. H.; MACIEL, M. L. (Org.). Conhecimento, sistema de inovação e desenvolvimento. Rio de Janeiro: Editora da UFRJ/Contraponto, 2005.

CHENEY, P. K.; DEVINNEY, T.; WIRIER, R. S. The impact of new product introductions on the market value of firms. The Journal of Business, v. 64, n. 4, p. 573-610, 1991.
COLBARI, A. Agentes de Desenvolvimento e Agentes de Inovação: a integração dos pequenos empreendimentos às dinâmicas socioeconômicas locais. In: DALLA COSTA, A.; ETCHEVERRY, M. S.; GROS, D. B.; MINELLA, A. C.; IGLECIAS, W. (Org.). Desenvolvimento e crise na América Latina: estado, empresas e sociedade. Curitiba: Editora CRV, 2012. p. 91-112.

CONFEDERAÇÃO NACIONAL DA INDÚSTRIA (CNI). Agenda Legislativa da Indústria 2012. Brasília: [s.n.], 2012. Disponível em: <www.cni.org.br>. Acesso em: 20 maio 2012.

. Políticas públicas de inovação no Brasil: a agenda da indústria. Confederação Nacional da Indústria. Brasília: [s.n.], 2005.

CONFEDERAÇÃO NACIONAL DE MUNICÍPIOS (CNM); SERVIÇO BRASILEIRO DE APOIO ÀS MICRO E PEQUENAS EMPRESAS (SEBRAE). Manual de desenvolvimento dos municípios. Brasília: CNM/SEBRAE, 2011.

DIAZ-ISENRATH, M. C. Máquinas de pesquisa: o estatuto do saber no capitalismo informacional. 2008. Tese (Doutorado em Ciências Sociais) - Programa de Pós-Graduação em Ciências Sociais, Universidade de Campinas, Campinas, 2008.

DUBAR, C. A crise das identidades: a interpretação de uma mutação. São Paulo: Editora da Universidade de São Paulo, 2009.

FONTENELLE, I. A. Para uma crítica ao discurso da inovação: saber e controle no capitalismo do conhecimento. RAE - Revista de Administração de Empresas, São Paulo, v. 52, n. 1, p. 100-108, jan./fev. 2012.

. Pós-modernidade: trabalho e consumo. São Paulo: Cengage Learning, 2008.

GRANOVETTER, M. Small is Bountiful: Labor Markets and Establishment. American Sociological Review, Washington, DC, v. 49, n. 3, p. 323-334, jun. 1984.

GUIMARÃES, S. K. Empreendedorismo intensivo em conhecimento no Brasil. Caderno CRH, Salvador, v. 24, n. 63, p. 575-591, set./dez. 2011.

HALL, B. H. The relationship between firm size and firm growth in the US manufacturing sector. The Journal of Industrial Economics, Wiley Blackwell, v. 35, n. 4, p. 583-606, jun. 1987.

INSTITUTO DE PESQUISA ECONÔMICA APLICADA (IPEA). Brasil em desenvolvimento 2011: Estado, planejamento e políticas públicas. Brasília: IPEA, 2012.

LUNDVALL, B. Políticas de Innovación en la economia de aprendizaje. Revista Latinoamericana de Estudios del Trabajo, Buenos Aires, ano 8, n. 16, p. 117-138, jan./dez. 2003.

MACIEL, M. L. Ciência, tecnologia e inovação: a relação entre tecnologia e desenvolvimento. BIB, São Paulo, n. 54, p. 67-82, jun./dez. 2002.

MINISTÉRIO DO DESENVOLVIMENTO, INDÚSTRIA E COMÉRCIO EXTERIOR (MDIC). Fórum Permanente das Microempresas e Empresas de Pequeno Porte, nov. 2007.

NARETTO, N.; BOTELHO, M. R.; MENDONÇA, M. A trajetória das políticas públicas para pequenas e médias empresas no Brasil: do apoio individual ao apoio a empresas articuladas em arranjos produtivos locais. 
Planejamento e Políticas Públicas, Brasília, v. 27, p. 61-115, jun./dez. 2004.

ORGANIZAÇÃO PARA A COOPERAÇÃO ECONÔMICA E DESENVOLVIMENTO (OCDE); FINANCIADORA DE ESTUDOS E PROJETOS (FINEP). Manual de Oslo. Proposta de Diretrizes para Coleta e Interpretação de Dados sobre Inovação Tecnológica. Brasília: OCDE/ FINEP, 2004.

PORTER, M. E. Vantagem competitiva. Rio de Janeiro: Campus, 1989.

SALERNO, M. S.; KUBOTA, L. C. Estado e Inovação. In: NEGRI, J. A.: KUBOTA, L. C. (Org). Politicas de incentivo à inovação tecnológica. Brasília: IPEA, 2008.

SANTOS, M. O espaço dividido: os dois circuitos da economia urbana dos países subdesenvolvidos. São Paulo: Edusp, 2004. [1979].

SCHUMPETER, J. A. A Teoria do desenvolvimento econômico. São Paulo: Abril Cultural, 1982.

SERVIÇO BRASILEIRO DE APOIO ÀS MICRO E PEQUENAS EMPRESAS (SEBRAE); Universidade Corporativa SEBRAE (UCSEBRAE). Unidade Temática 2. O Sebrae e o agente local de inovação: uma contextualização. Guia do educador. Brasília: Sebrae, 2011.

SERVIÇO BRASILEIRO DE APOIO ÀS MICRO E PEQUENAS EMPRESAS-ES (SEBRAE-ES). Apresentação dos dados finais do projeto ALI-ES elaborado a partir da comparação entre os Diagnósticos de Inovação. Vitória: Sebrae-ES, 2012.
SERVIÇO BRASILEIRO DE APOIO ÀS MICRO E PEQUENAS EMPRESAS-SP (SEBRAE-SP). Inovação $e$ competitividade nas MPEs brasileiras. São Paulo: SebraeSP, set. 2009.

SERVIÇO BRASILEIRO DE APOIO ÀS MICRO E PEQUENAS EMPRESAS (SEBRAE); DEPARTAMENTO INTERSINDICAL DE ESTATÍSTICA E ESTUDOS SOCIOECONOMICOS (DIEESE). Anuário do trabalho na micro e pequena empresa: 2012. 5. ed. Brasília, DF: SEBRAE/ DIEESE, 2012. Disponível em: <http://www.sebrae. com.br/estudos-e-pesquisas>. Acesso em: 10/12/2012.

SOBRAL, F. A. F. Novos horizontes para a produção científica e tecnológica. Caderno CRH, Salvador, v. 24, n. 63, p. 519-534, set./dez. 2011.

THRIFT, N. The rise of soft capitalism. Cultural Values, London, v. 1, n. 1, p. 25-71, 1997.

Knowing capitalism. London: Sage, 2005.

TIDD, J. Innovation management in context: environment, organization and performance. International Journal of Management Reviews, London, v. 3, n. 3, p. 169-183, set. 2001.

VALE, G. M. V.; WILKINSON, J.; AMÂNCIO, A. Empreendedorismo, inovação e redes: uma nova abordagem. RAE-eletrônica, Bela Vista, v. 7, n. 1, jan./jun. 2008. Disponível em: <www.rae.com.br/eletronica>. Acesso em: 13 jun. 2013. 